\title{
A mitral blood cyst causing stenosis in the left ventricular outflow tract: A case report
}

\author{
Berra Zümrüt Tan Recep (D), Eylem Tuncer (D), Hakan Ceyran (D) \\ Department of Cardiovascular Surgery, Kartal Koşuyolu Yüksek Ihtisas Training and Research Hospital, Istanbul, Turkey
}

Received: January 04, 2021 Accepted: March 31, 2021 Published online: August 11, 2021

\begin{abstract}
Intracardiac blood cysts are commonly observed in the autopsies of fetuses and infants. Most patients are below six months of age, and most cysts spontaneously regress with aging. Intracardiac blood cysts are rarely described in children and adults. A nine-year-old girl was admitted to our clinic with atypical chest pain. Echocardiography revealed a cystic formation on the anterior mitral leaflet. The cyst caused the obstruction of the left ventricular outflow tract. The patient was evaluated by a multidisciplinary team, and surgical intervention was decided. After cyst resection, the mitral valve did not require further intervention. Histopathological examination confirmed that the cyst was a mitral blood cyst. The patient was discharged without any postoperative complications.
\end{abstract}

Keywords: Cardiac tumor, left ventricular outflow tract stenosis, mitral blood cyst.

First reported by Elässer ${ }^{[1]}$ in 1844 , intracardiac blood cysts are rare lesions. As detailed by Khan et a1., ${ }^{[2]}$ blood cysts are thin-walled cysts filled with non-organized thrombi. In 1983, Hausser et al. ${ }^{[3]}$ used echocardiography to demonstrate the movement of the hypoechoic structure and the site of attachment.

Blood cysts are most commonly seen in the mitral and tricuspid valves, and rarely affect the pulmonary or aortic valve. Until 2009, mitral blood cysts were seen in eleven patients and 81.8 of these mitral cysts caused from anterior leaflet. Intracardiac cysts are associated with a variety of symptoms, including shortness of breath, chest pain at rest and during exertion, and even syncope; however, neurological deficits are less common and are associated with embolic stroke or transient ischemic attack following cyst rupture. ${ }^{[4]}$ In this article, we report a case of a mitral blood cyst causing stenosis in the left ventricular outflow tract.

\section{CASE REPORT}

A nine-year-old girl was referred to our clinic from an external center, after a blood cyst was detected in the mitral valve following atypical chest pain. There were no signs of previous disease. Electrocardiogram did not reveal arrhythmia or significant ST-segment or $\mathrm{T}$ wave changes. Echocardiography revealed a $25 \times 20-\mathrm{mm}$ blood cyst attached to the ventricular side of the anterior mitral leaflet that protruded toward the left ventricular outflow tract during each systole and led to an increased mean mitral valve gradient of $25 \mathrm{mmHg}$ (Figure 1). The findings were confirmed by transesophageal echocardiography. During surgery, aortotomy revealed a thin-walled lobular cystic formation attached to the anterior mitral leaflet. The cyst was excised (Figure 2). Surgical inspection did not reveal any mitral valve defects. Postoperative transesophageal echocardiography did not reveal mitral regurgitation or a pressure gradient in the left ventricular outflow tract. The patient was discharged without any complications. The pathological examination confirmed that the mass was a blood cyst. A written informed consent was obtained from the parents and/or legal guardians of the patient.

Corresponding author: Berra Zümrüt Tan Recep, MD. Kartal Koşuyolu Yüksek İhtisas Eğitim ve Araştırma Hastanesi Kalp ve Damar Cerrahisi Kliniği, 34865 Kartal, İstanbul, Turkey.

Tel: +90 216 - 5001500 e-mail: dr.bzt@hotmail.com

\section{Citation:}

Tan Recep BZ, Tuncer E, Ceyran H. A mitral blood cyst causing stenosis in the left ventricular outflow tract: A case report. Cardiovasc Surg Int 2021;8(2):116-118. 


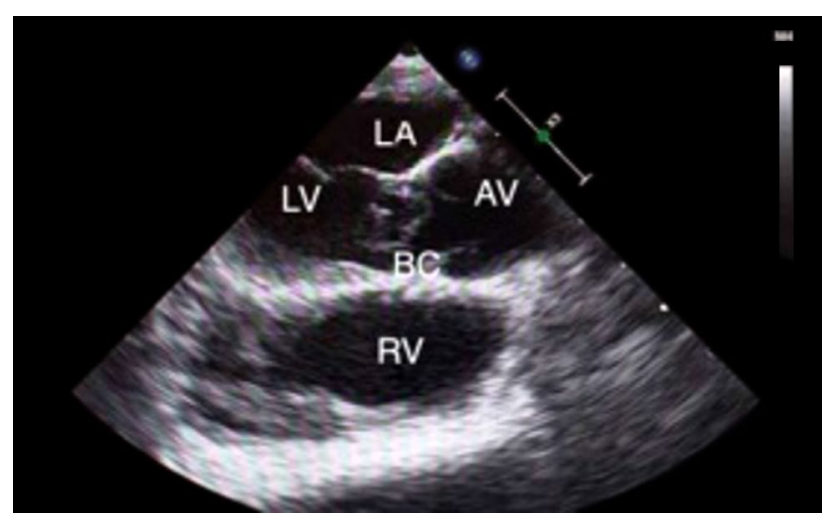

Figure 1. Preoperative echocardiography showing cystic appearance.

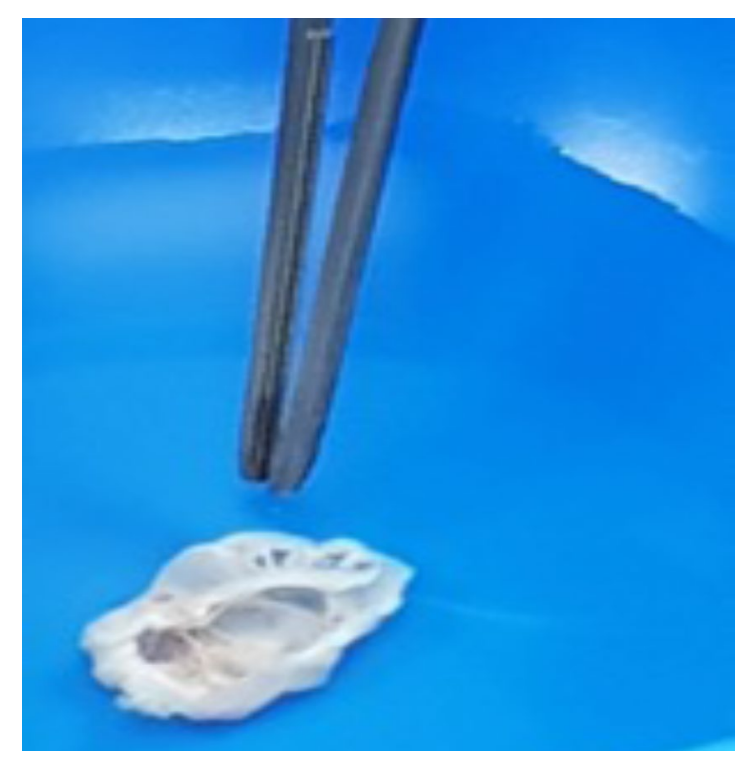

Figure 2. An intraoperative view after cyst excision.

\section{DISCUSSION}

Most intracardiac masses are tumors, and $90 \%$ are benign. Myxoma is the most common intracardiac tumor in $70 \%$ of cases. ${ }^{[5]}$ Other possible causes of intracardiac tumors include endocarditis, fibroelastoma, cardiac metastasis, or vegetation in the mitral valve. ${ }^{[6]}$

Echocardiography is a reliable method for the diagnosis of blood cysts. The appearance of a hypoechoic cyst in the absence of signs of systemic disease should raise suspicion for a blood cyst. Transesophageal echocardiography is critical in the differential diagnosis between cysts and thrombus. The demonstration of the intramural contrast in contrast-enhanced echocardiography is a pathognomonic sign of blood cysts. ${ }^{[7]}$ Magnetic resonance imaging has been shown to be superior in the assessment of intracardiac masses and their differential diagnosis, although histopathological examination is currently the gold standard. ${ }^{[8]}$

Several theories have been proposed regarding the formation of intracardiac blood cysts. These include dilation of the vascular space, heteroplastic tissue changes, inflammation, anoxia, and hemorrhagic diathesis. The underlying mechanism of the formation of intracardiac blood cysts is still unclear. ${ }^{[8]}$ In rare cases, a causal relationship cannot be established between cyst formation and a known factor; however, blood cyst formation secondary to a hematoma has been reported in several cases with a history of cardiac surgery. ${ }^{[9]}$

There is no consensus or any guidelines on the optimal management of blood cysts. The vast majority of patients with mitral blood cysts require surgical resection. ${ }^{[10]}$ Pelikan et al. ${ }^{[11]}$ reported that asymptomatic cysts could be monitored by echocardiography due to their benign nature and that resection should be reserved for patients with impaired cardiac functions. Paşaoğlu et al. ${ }^{[12]}$ recommended the resection of cystic tumors of the heart, particularly valvular cysts. However, surgical resection is usually recommended for symptomatic patients, ${ }^{[1,13]}$ large tumors, valvular dysfunction, ${ }^{[14]}$ or patients who are asymptomatic, but would undergo open heart surgery for other reasons. ${ }^{[15]}$

Khan et al. ${ }^{[2]}$ also reported that as blood cysts were associated with the intracardiac cavity, and their rupture might cause systemic and coronary embolization. They recommended that asymptomatic small cysts should be monitored, while patients should be administered anticoagulant therapy due to the risk of thromboembolism.

In our patient, there were no other etiologies to explain chest pain, and the cyst was associated with the anterior mitral leaflet and protruded into the left ventricular outflow tract in each systole, thereby, creating a pressure gradient. Therefore, surgical resection was decided. Surgery allows confirmation of the diagnosis through the pathological examination, and the elimination of malignancy. However, follow-up with serial echocardiographic imaging may be a viable option for asymptomatic or inoperable patients. 
In conclusion, although rare, blood cysts should be considered in the differential diagnosis of hypoechoic masses as evidenced by echocardiography. There are no available data on the long-term follow-up of patients with intracardiac blood cysts. The cysts can be fully surgically resected. If a valvular defect or a disruption of valvular coaptation occur after surgical excision, it should be corrected simultaneously.

\section{Declaration of conflicting interests}

The authors declared no conflicts of interest with respect to the authorship and/or publication of this article.

\section{Funding}

The authors received no financial support for the research and/or authorship of this article.

\section{REFERENCES}

1. Elsässer C. Bericht über die Ereignisse in der Gebäranstalt des Catherinen-Hospital im Jahre 1844. Med Correspondenzblatt 1844;14:297.

2. Khan T, El-Sharkawy S, Schafer F. A heart within the heart-a rare congenital cause of an embolic stroke. BMJ Case Rep 2012;2012:bcr1020115027.

3. Hauser AM, Rathod K, McGill J, Rosenberg BF, Gordon S, Timmis GC. Blood cyst of the papillary muscle. Clinical, echocardiographic and anatomic observations. Am J Cardiol 1983;51:612-3.

4. Ramírez-Mesías DC, Contreras-Valero JF, Pinilla-Monsalve GD, Vesga-Reyes CE. Blood cyst of the mitral valve diagnosed in an adult after systemic thrombolysis. Case Rep Cardiol 2020;2020:4320269.
5. Thiene G, Valente M, Lombardi M, Basso C. Tumours of the heart. Cardiol 2003;92:890-5.

6. Halim J, van Schaagen FR, Riezebos RK, Lalezari S. Giant intracardiac blood cyst: Assessing the relationship between its formation and previous cardiac surgery. Neth Heart J 2015;23:392-4.

7. Bezak B, Artemiou P, Hudec V, Hulman M. Blood cyst of the anterior mitral leaflet causing severe mitral regurgitation. J Card Surg 2019;34:1354-5.

8. Randhawa K, Ganeshan A, Hoey ET. Magnetic resonance imaging of cardiac tumors: Part 2, malignant tumors and tumor-like conditions. Curr Probl Diagn Radiol 2011;40:169-79.

9. Bagheri A, Ansariaval Z, Khani M, Shekarkhar S, Baghayi $\mathrm{R}$, Sharifi T. Two adherent blood cysts in subvalvular apparatus of the mitral valve causing severe left ventricular outflow tract obstruction. J Cardiol Cases 2018;18:78-80.

10. Dencker M, Jexmark T, Hansen F, Tydén P, Roijer A, Lührs C. Bileaflet blood cysts on the mitral valve in an adult. J Am Soc Echocardiogr 2009;22:1085.e5-8.

11. Pelikan HM, Tsang TS, Seward JB. Giant blood cyst of the mitral valve. J Am Soc Echocardiogr 1999;12:1005-7.

12. Paşaoğlu I, Doğan R, Nazli N, Güngen Y, Bozer AY. Blood cyst originating from tricuspid septal leaflet. J Cardiovasc Surg (Torino) 1991;32:589-91.

13. Park MH, Jung SY, Youn HJ, Jin JY, Lee JH, Jung HO. Blood cyst of subvalvular apparatus of the mitral valve in an adult. J Cardiovasc Ultrasound 2012;20:146-9.

14. Ansari E, Akhyari P, Lichtenberg A. Blood cyst of the anterior leaflet of the mitral valve in an asymptomatic adult: Is surgery an objective? Heart Surg Forum 2015;18:E196-7.

15. Donndorf P, Bermaoui B, Westphal B, Steinhoff G. Asymptomatic blood cyst of the papillary muscle in an adult undergoing coronary bypass surgery. Interact Cardiovasc Thorac Surg 2013;16:402-4. 